\title{
Polymorphisms in Plasmodium vivax antifolate resistance markers in Afghanistan between 2007 and 2017
}

\author{
Kasama Rakmark', Ghulam R. Awab 2,3, Jureeporn Duanguppama ${ }^{1,4}$, Usa Boonyuen ${ }^{1}$, Arjen M. Dondorp ${ }^{3,4}$ \\ and Mallika Imwong $1,3,4^{*}$ (D)
}

\begin{abstract}
Background: Plasmodium vivax is the predominant Plasmodium species in Afghanistan. National guidelines recommend the combination of chloroquine and primaquine (CQ-PQ) for radical treatment of $P$. vivax malaria. Artesunate in combination with the antifolates sulfadoxine-pyrimethamine (SP) has been first-line treatment for uncomplicated falciparum malaria until 2016. Although SP has been the recommended treatment for falciparum and not vivax malaria, exposure of the P. vivax parasite population to SP might still have been quite extensive because of community based management of malaria. The change in the P. vivax antifolate resistance markers between 2007 and 2017 were investigated.
\end{abstract}

Methods: Dried blood spots were collected $(n=185)$ from confirmed P. vivax patients in five malaria-endemic areas of Afghanistan bordering Tajikistan, Turkmenistan and Pakistan, including Takhar, Faryab, Laghman, Nangarhar, and Kunar, in 2007, 2010 and 2017. Semi-nested PCR, RFLP and nucleotide sequencing were used to assess the pyrimethamine resistant related mutations in P. vivax dihydrofolate reductase (pvdhfr I13L, P33L, N50I, F57L, S58R, T61I, S93H, $\mathrm{S} 117 \mathrm{~N}, 1173 \mathrm{~L}$ ) and the sulfonamide resistance related mutations in P. vivax dihydropteroate synthase (pvdhps A383G, A553G).

Results: In the 185 samples genotyped for pvdhfr and pvdhps mutations, 11 distinct haplotypes were observed, which evolved over time. In 2007, wild type pvdhfr and pvdhps were the most frequent haplotype in all study sites $(81 \%, 80 / 99)$. However, in 2017 , the frequency of the wild-type was reduced to $36 \%$, $(21 / 58 ; p$ value $\leq 0.001)$, with an increase in frequency of the double mutant $p v d h f r$ and pvdhps haplotype $\operatorname{S58RS117N~}(21 \%, 12 / 58)$, and the single pvdhfr mutant haplotype S117N (14\%, 8/58). Triple and quadruple mutations were not found. In addition, pvdhfr mutations at position N50I $(7 \%, 13 / 185)$ and the novel mutation S93H $(6 \%, 11 / 185)$ were observed. Based on in silico protein modelling and molecular docking, the pvdhfr N50l mutation is expected to affect only moderately pyrimethamine binding, whereas the $\mathrm{S} 93 \mathrm{H}$ mutation does not.

Conclusions: In the course of ten years, there has been a strong increase in the frequency pyrimethamine resistance related mutations in pvdhfr in the $P$. vivax population in Afghanistan, although triple and quadruple mutations conferring high grade resistance were not observed. This suggests relatively low drug pressure from SP on the $P$. vivax

\footnotetext{
*Correspondence: noi@tropmedres.ac

${ }^{1}$ Department of Molecular Tropical Medicine and Genetics, Faculty

of Tropical Medicine, Mahidol University, 420/6 Rajvithi Road, Bangkok 10400, Thailand

Full list of author information is available at the end of the article
}

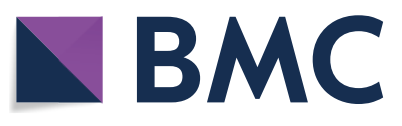

(c) The Author(s) 2020. This article is licensed under a Creative Commons Attribution 4.0 International License, which permits use, sharing, adaptation, distribution and reproduction in any medium or format, as long as you give appropriate credit to the original author(s) and the source, provide a link to the Creative Commons licence, and indicate if changes were made. The images or other third party material in this article are included in the article's Creative Commons licence, unless indicated otherwise in a credit line to the material. If material is not included in the article's Creative Commons licence and your intended use is not permitted by statutory regulation or exceeds the permitted use, you will need to obtain permission directly from the copyright holder. To view a copy of this licence, visit http://creativeco mmons.org/licenses/by/4.0/. The Creative Commons Public Domain Dedication waiver (http://creativecommons.org/publicdomain/ zero/1.0/) applies to the data made available in this article, unless otherwise stated in a credit line to the data. 
parasite population in the study areas. The impact of two newly identified mutations in the pvdhfr gene on pyrimethamine resistance needs further investigation.

Keywords: Plasmodium vivax, Antifolate resistance, Dihydrofolate reductase (DHFR) and dihydropteroate synthase (DHPS), Afghanistan

\section{Background}

With a sharp decline in falciparum malaria, Plasmodium vivax has become the prominent Plasmodium species in Afghanistan causing more than $95 \%$ of all malaria cases [1]. The recommended first-line treatment for vivax malaria in Afghanistan is chloroquine combined with primaquine for radical cure (CQ-PQ), whereas for uncomplicated falciparum malaria the combination of artesunate and sulfadoxine-pyrimethamine (AS-SP) has been first-line treatment from 2003 to 2016, replaced by artemether-lumefantrine since 2016. Although SP has been the recommended treatment for falciparum and not vivax malaria, exposure of the $P$. vivax parasite population to SP might still have been quite extensive because of community based management of malaria particularly symptom-based clinical or probable diagnosed malaria in past two decades $[2,3]$ and SP treatment of vivax malaria in parts of the private sector or through self-medication [3]. This might have increased antifolate resistance in $P$. vivax in Afghanistan.

Dihydrofolate reductase (DHFR) and dihydropteroate synthase (DHPS) are 2 essential enzymes in de novo folate synthesis pathway in Plasmodium and the drug targets of pyrimethamine, and sulfadoxine, respectively [4]. SP is considered a sub-optimal treatment for $P$. vivax infections, because this parasite is intrinsically less sensitive to sulfonamides and resistance to SP is rapidly acquired with extensive drug exposure [5]. Through clinical, epidemiological, molecular and biochemical studies it has been identified that SP resistance in $P$. vivax is conferred by specific point mutations in the $P$. vivax dihydrofolate reductase $(p v d h f r)$ and dihydropteroate synthase (pvdhps) genes. In areas with extensive SP use, treatment failure of vivax malaria with SP rapidly evolved, and was associated with mutations in codons $57,58,61,117$, 173 of pvdhfr and in codons 382, 383, and 553 of pvdhps [6-10].

The frequencies of SP resistance related $p v d h f \mathrm{r}$ and pvdhps mutations have been extensively reported from various malaria-endemic areas, including Thailand [8, 11-14], Cambodia [15], Myanmar [16], Vietnam [17], Indonesia [18], Papua New Guinea [19], Madagascar [20] and India [21-24]. However, reports from Afghanistan and Middle East countries are scarce. Previous studies from Afghanistan [25], Iran [26, 27], Pakistan [28-31] showed a majority of $P$. vivax strains carried wild-type $p v d h f \mathrm{r}$ and $p v d h p s$, and a low frequency in $p v d h f r$ of the double mutation in codon S58R/ S117N and single mutation in codon S117N.

In this study, the frequency of SP resistance related point mutations in the $P$. vivax $p v d h f r$ and pvdhps genes in Afghanistan over time between 2007 and 2017 were reported. In addition, in silico three-dimensional modelling and molecular docking of 2 newly identified $p v d$ $h f r$ mutationswere performed to predict their impact on pyrimethamine sensitivity.

\section{Methods}

\section{Study sites and sample collection}

Dried blood spots $(\mathrm{n}=185)$ from patients with light microscopy confirmed $P$. vivax infection were collected from five malaria endemic provinces in Afghanistan. In 2007 samples were collected from Takhar (bordering Tajikistan), Faryab (bordering Turkmenistan), and Nangarhar (bordering Pakistan). In 2010, samples were collected from Kunar and in 2017 from Nangarhar and Laghman, all bordering Pakistan. Blood samples of 20-30 $\mu \mathrm{l}$ were collected onto filter paper at the moment of patient presentation before antimalarial treatment. Genomic DNA was extracted by using QIAmp ${ }^{\circledR}$ DNA Mini Kit (Qiagen, Hilden, Germany), according to the manufacturer's instructions and purified DNA was stored at $-20^{\circ} \mathrm{C}$ until further processing. Approval for this study was obtained from the Ethics Review Committee for Research in Human Subjects, Faculty of Tropical Medicine, Mahidol University, Thailand (EC approval number MUTM 2019-065-01).

In this study, the frequency of mixed infection of falciparum and vivax malaria was investigated by nested PCR detected 18S rRNA of Plasmodium spp. [32], only one sample was $P$. vivax and $P$. falciparum mixed infection $(0.54 \%, 1 / 185)$. The low frequency of mixed infection of $P$. vivax and $P$. falciparum was explained by $P$. falciparum infected samples were excluded in the beginning.

\section{Pvdhfr and pvdhps amplification and genotyping}

Amplification of $p v d h f r$ by semi-nested Polymerase Chain Reaction was performed following established and published methods protocols [8, 23]. For amplification, the primary and secondary reaction volumes were 25 and $100 \mu \mathrm{l}$, respectively, including $1 \mu \mathrm{l}$ of template genomic DNA added in the primary amplified reaction, and $3 \mu \mathrm{l}$ of primary amplified product added to the second round of 
amplification. The reaction mixture contained a final concentration of $125 \mathrm{nM}$ primers forward-reverse mixture, 10 mM Tris-HCL (pH 8.3), 2 mM MgCl2, $125 \mu \mathrm{M}$ dNTP mixture, and 0.4 U Taq polymerase (Invitrogen, Carlsbad, CA) (Additional file 1: Table S1-S7). The DNA fragments from PCR amplification or Restriction Fragment Length Polymorphism (New England BioLabs Inc., Ipswich, MA) were identified by $3 \%$ metaphor agarose gel electrophoresis (Radnor Corporate Center Radnor, PA). The amplified PCR product of $p v d h f r$ was purified for DNA sequencing using PCR purification kit, FavorPrep ${ }^{\text {TM }}$ (Favorgen, Taiwan). The purified PCR products of $p v d h f r$ were sequenced by Macrogen, Korea. Nucleotide and amino acid sequences of this gene were aligned and compared with the $P$. vivax reference sequence from the original Sal1 strain (accession no. XM001615032), using BioEdit v7.2.5. For identification of established gene mutations associated with sulfonamide resistance, genotyping of pvdhps used PCR-RFLP methods, following established and published protocols [33]. The positive control of $P$. vivax is genomic DNA from SalI reference strain and characterized $P$. vivax isolates from the patient. To ensure the accuracy of the results, two positive controls and negative controls were added for quality control at every step of the procedure.

\section{In silico modelling of mutant PvDHFR}

A computer simulated three-dimensional model of the PvDHFR protein structure and its putative interactions with pyrimethamine was used to predict the impact of $p v d h f r$ mutations on pyrimethamine binding. The wildtype PvDHFR structure (PDB ID: 2BL9) was used as a template for mutant PvDHFR modelling. The model was constructed using SWISS-MODEL (https://swiss model.expasy.org). The constructed model was verified by PROCHECK [34]. Then, the derived structures of the active sites of mutant PvDHFR were complexed with pyrimethamine and evaluated by AutoDock Vina [35]. The structural models were visualized by Discovery Studio Visualizer-Accelrys.

\section{Statistical analysis}

The data of SNPs frequency related drug resistant genes were analysed by using MS Excel and SPSS v26.0. IBM Corp., Armonk, NY, USA. Pearson's Chi-square test was used to compare proportions of haplotypes. A $P$ value $<0.05$ was considered statistically significant.

\section{Results}

\section{Pvdhfr and pvdhps haplotypes}

A total of 185 dry blood spots from patients presenting with vivax malaria were collected from the study sites. In the 185 genotyped samples, a total of 11 distinct $p v d h f r$ and pvdhps haplotypes could be distinguished. Overall, the wild-type haplotype was the most frequent (64\%, 119/185) (Table 1). Two other common haplotypes were a single mutant haplotype S117N $(10 \%, 19 / 185)$ and a double mutant haplotype S58RS117N (9\%, 16/185). Rare haplotypes included a mutation at codon position 383 of pvdhps in combination with pvdhfr single mutation at position 117; S117N/A383G (1\%, 2/185) and a $p v d h f r$ double mutations at 58 and 117; S58RS117N/A383G (1\%, 1/185). The mutation A383G of pvdhps was detected in 8\%, (3/37) of samples from Nangarhar in 2017.

A novel mutation at codon S93H (AGC to $\underline{\mathrm{CAC}}$ ) was identified comprising a single mutant haplotype $\mathrm{S} 93 \mathrm{H}$ $(4 \%, 8 / 185)$ and a double mutant haplotype S93HS117N $(2 \%, 3 / 185)$ (Table 1$)$. The N50I mutation (AA to ATC) observed in this study had not been described from Afghanistan before. The mutation was part of the single N50I mutation haplotype present in 2\% (3/185) of samples. While double mutant haplotype N50IS117N was found in 5\% (10/185) of samples. Haplotypes with triple or quadruple mutations, which are associated with high grade antifolate resistance, were not observed in this study.

\section{Temporal changes in pvdhfr and pvdhps haplotypes between 2007 and 2017}

In 2007, the wild type $p v d h f r$ and $p v d h p s$ haplotype was most frequent $(81 \%, 80 / 99)$. Other haplotypes were rare, including the single mutant haplotype S117N in 6\%, (6/99), and the double mutant haplotype N50IS117N in 3\% (3/99) of samples. Also in the year 2010 the wild type $p v d h f r$ and pvdhps haplotype was most frequent $(64 \%, 18 / 28)$. The single mutant haplotype S117N $(18 \%, 5 / 28)$ and double mutant haplotype S58RS117N $(11 \%, 3 / 28)$ were also observed. In contrast in 2017, the frequency of wild-type $p v d h f r$ and $p v d h p s$ haplotype was compared to 2007 significantly reduced to $36 \%(21 / 58)$ of samples ( $p$ value $\leq 0.001)$. In 2017, the frequencies of the single mutant haplotype S117N $(14 \%, 8 / 58, p$ value $\leq 0.001)$ and double mutant haplotype S58RS117N had increased significantly (21\%, $12 / 58, p$ value $\leq 0.001)($ Table 1$)$ (Figs. 1, 2).

\section{In silico modelling of novel pvdhfr mutations}

Since the two nonsynonymous $p v d h f r$ mutation at position N50I, AAC (Asn) to ATC (Ile), and S93H, AGC (Ser) to $\underline{C A C}$ (His) had not been observed earlier in Afghanistan, the corresponding three-dimensional structures of the mutated proteins and the impact on pyrimethamine binding were modelled and predicted. The mutation N50I is located within the binding pocket, approximately $5 \AA$ from the pyrimethamine molecule but does not directly interact with the drug. The mutation $\mathrm{S} 93 \mathrm{H}$ is placed on the other side of the protein molecule, far away from the binding pocket (Figs. 3, 4, 5). Replacement of 


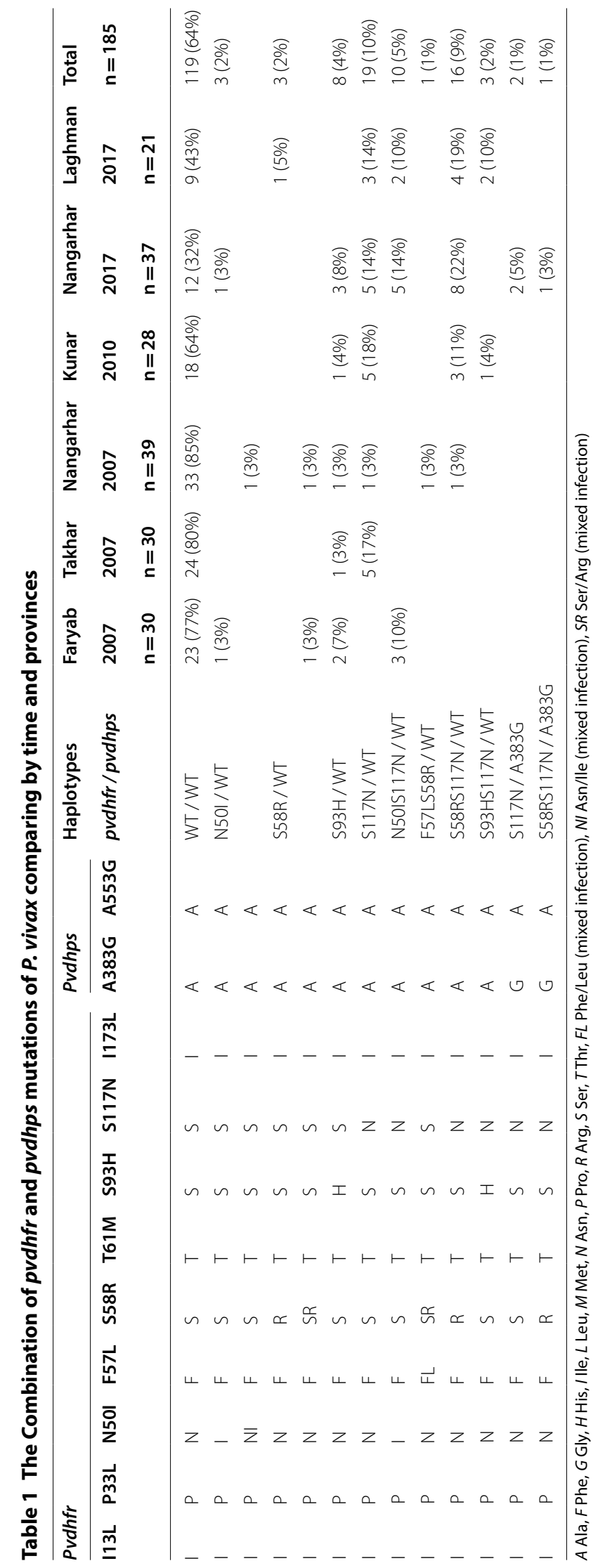




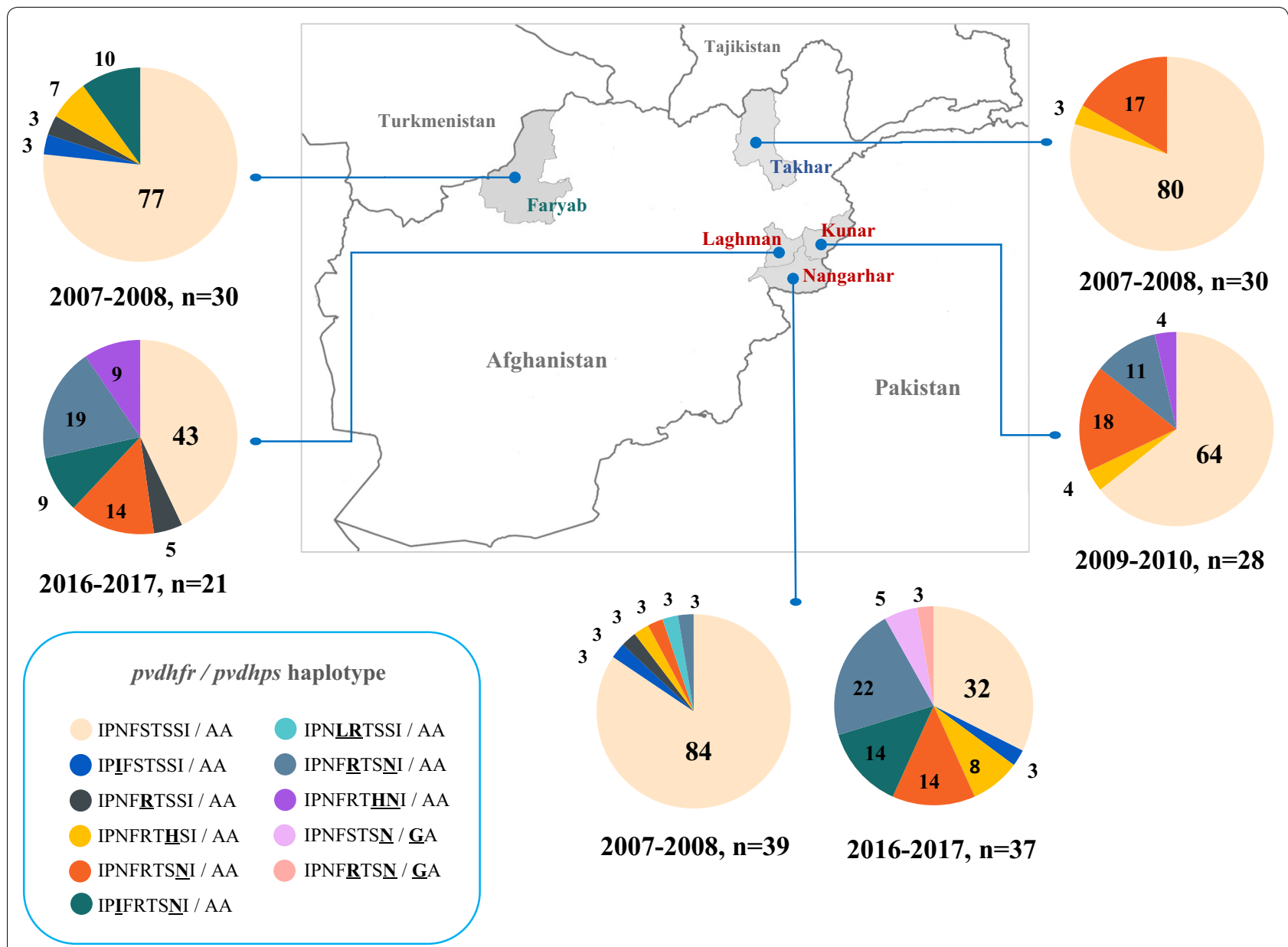

Fig. 1 Frequencies of mutations (\%) in pvdhfr and pvdhps in five border provinces of Afghanistan. Nine non-synonymous mutant codons of pvdhfr; 113L, P33L, N50I, F57L, S58R, T61I, S93H, S117N, 1173L and 2 codon non-synonymous mutant codons of pvdhps; A383G, A553G were observed

Asn with Ile at position 50 disrupts the hydrogen bonds between Asn and water molecules. The N50I mutation also causes a conformation rearrangement of the helix (residues 50-63), disturbing the favorable interactions between the enzyme and inhibitor. The model predicted that the $p v d h f r$ N50I mutation would affect only moderately pyrimethamine binding, whereas the $\mathrm{S} 93 \mathrm{H}$ mutation would not affect binding.

\section{Discussion}

The combination of AS-SP has been used as first-line treatment for uncomplicated.

P. falciparum in Afghanistan since 2003 to 2016, and SP has been widely available in private sectors for a long time. Since an episode of falciparum malaria triggers relapse infection with $P$. vivax a few weeks later, this provides a window of selection for resistant parasites to outgrow sensitive parasite still killed by the remaining SP drug levels. Drug pressure from SP on the $P$. vivax parasite population over the past decade is thus likely, which might cause gene mutations in $p v d h f r$ and pvdhps causing reduced SP sensitivity. Indeed, in this study, the frequency of the double mutant $p v d h f r$ haplotype at S58RS117N and single mutant haplotype at $\mathrm{S} 117 \mathrm{~N}$ had increased significantly over the course of ten years since 2007 were observed. However, the triple and quadruple haplotype mutations associated with higher level of antifolate resistance were not found, suggesting only low or moderate drug pressure from SP on the $P$. vivax parasite populations in the study areas.

These findings agree with previously published reports showing low prevalence (less than 5\%) of triple and quadruple mutant $p v d h f r$ and pvdhps haplotypes in $P$. vivax parasite populations from Iran, Pakistan and India (Table 2) [21, 22, 26-31, 36-39]. In the wider study region, it was observed that the pyrimethamine resistance marker at position 117 in $p v d h f r$ arose first and was followed by the subsequent mutation in positions 117 and 58, conferring increasing levels of resistance as report earlier [23, 26-31]. 


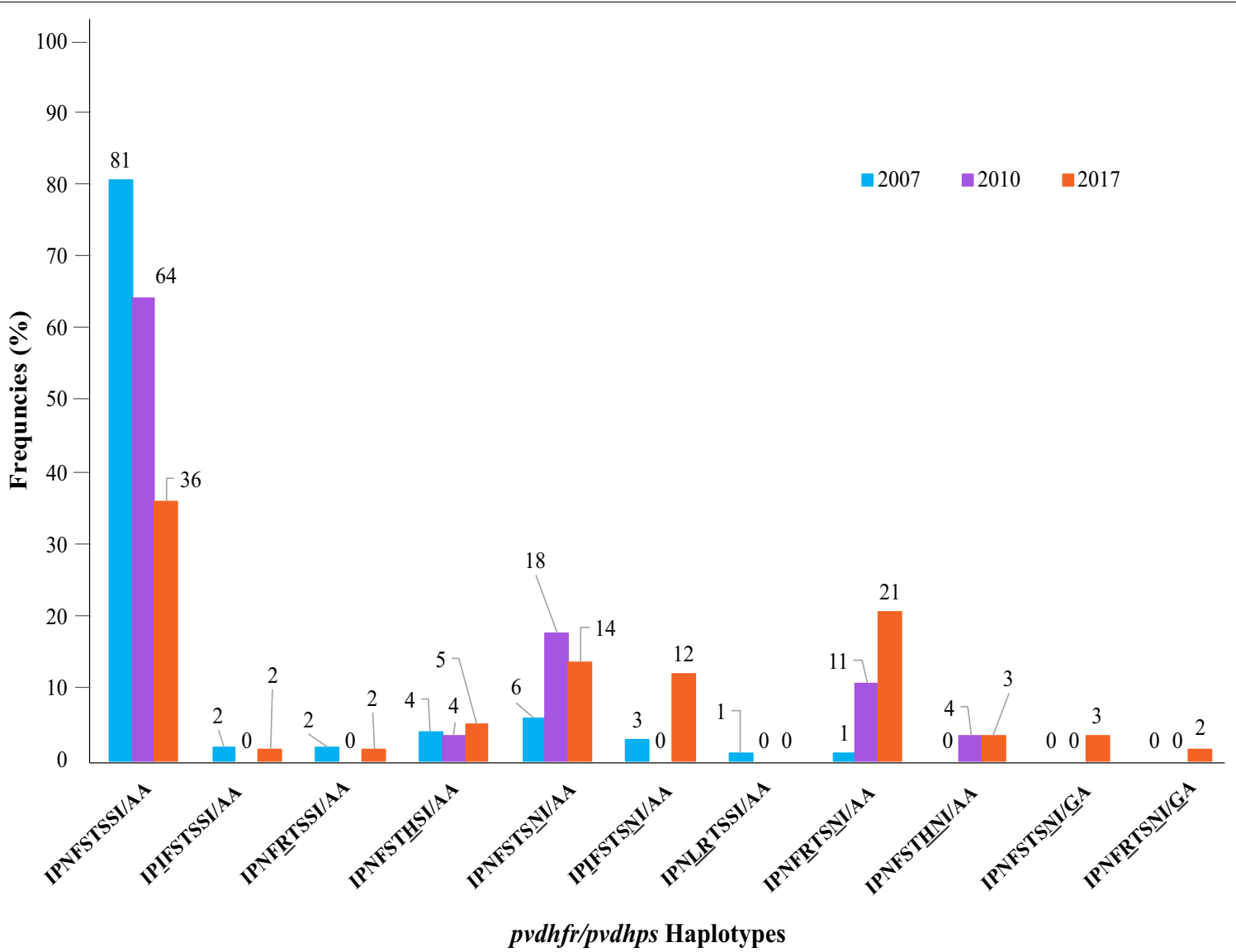

Fig. 2 Comparison of pvdhfr/pvdhps haplotype frequncies (\%) between year 2007 to 2017

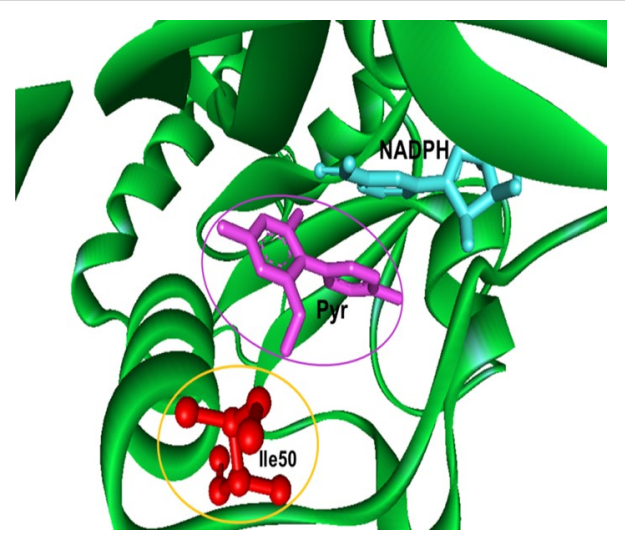

Fig. 3 Structural model of PvDHFR N50I mutation complexed with pyrimethamine. A mutation at position 50 (in yellow circle) is located within the binding pocket of pyrimrthamine (in purple circle)

Antifolate drugs inhibit two essential enzymes in the folate biosynthesis pathway, necessary for DNA precursor synthesis. Sulfadoxine inhibits DHPS while pyrimethamine inhibits DHFR, which results in parasite death

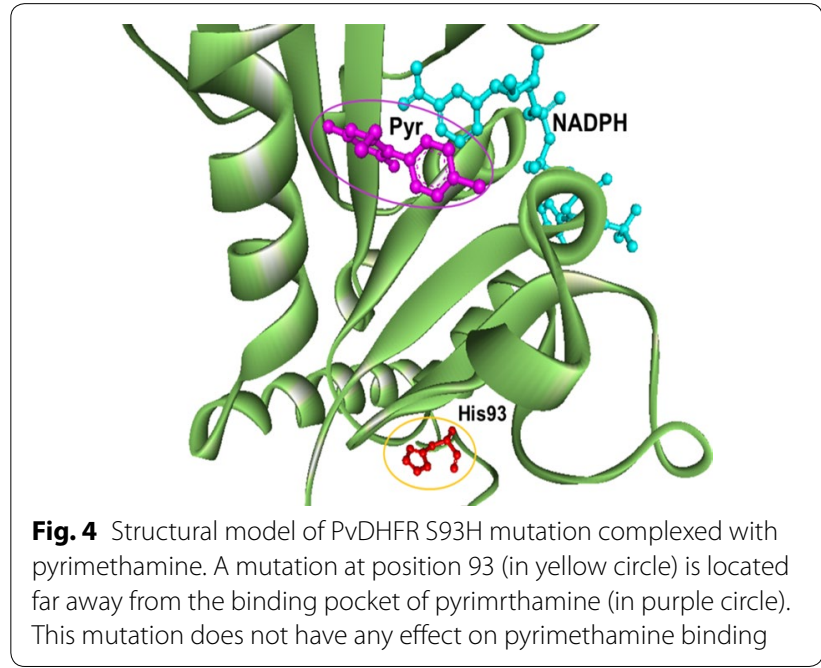

[4]. In P. falciparum, the intensive use of SP as first line treatment in south-east Asia since 1970s resulted in rapid acquisition of mutations in $p f d h f r$ and $p f d h p s$, causing amino acid changes in the enzymes at positions in 


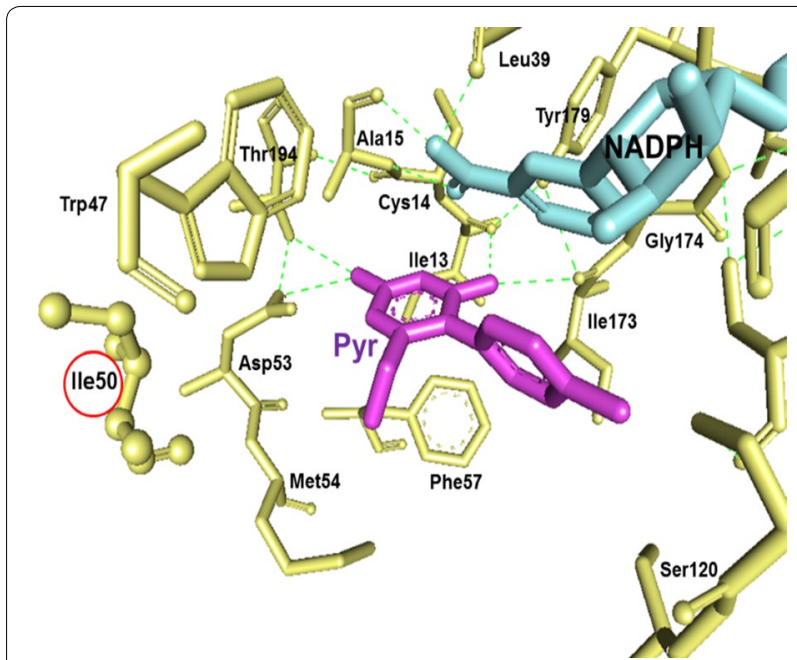

Fig. 5 Molecular interactions of pyrimethamine and PVDHFR. The binding analysis showed that mutation at position 50 (in red circle) is located approximately $5^{\circ} \mathrm{A}$ from pyrimethamine (purple) but not directly involved in the binding

the binding pockets for pyrimethamine and sulfadoxine, respectively, causing SP resistance $[7,8]$. The antifolate resistant mechanism in $P$. vivax, with incremental resistance acquired by the accumulation of single point mutations in $p v d h f r$ and $p v d h p s$, is thought to be similar to the antifolate resistance mechanism in P. falciparum. In $P$. vivax, the sequence of non-synonymous mutations in $p v d h f r$ is in codons $13,58,117,173$, equivalent to the orthologous pfdhfr positions 16, 59, 108 and 164 in P. falciparum. In $P$. vivax, biochemical and protein functional studies showed that pyrimethamine effectively inhibits wild-type PvDHFR, but were approximately 60 to $>4000$ times less active against mutant enzymes. Double mutant S58R and S117N PvDHFR was 10-25 fold less inhibited by pyrimethamine than the S117N mutant [10]. This relates to the steric hindering of the pyrimethamine binding pocket caused by the S117N mutation in the PvDHFR enzyme $[9,10]$.The studies also showed that a change in the effect of pyrimethamine on the enzyme kinetic properties of mutant PvDHFR is closely related with a change in sensitivity to pyrimethamine $[9,10]$.

The current study identified a novel nonsynonymous mutation $\mathrm{S} 93 \mathrm{H}$ in $p v d h f r$ and for Afghanistan newly observed N50I mutation in pvdhfr. The N50I mutation corresponds to the orthologous mutation N51I in $P$. falciparum. The $p v d h f r$ N50I mutation was previously observed in low frequency in Pakistan [29]. Previous study shown that mutant N50I PvDHFR expressed in yeast confers an increase in pyrimethamine $\mathrm{IC}_{50}$ compared to wild type PvDHFR, whereas, the combination of mutation N50I and S117N conferred a-57 fold increase in $\mathrm{IC}_{50}$ compared to wild type [40]. To assess the interaction of these mutations on pyrimethamine binding, homology modelling and molecular docking in-silico were performed. This showed that the pvdhfr N50I mutation interrupted moderately the binding of pyrimethamine. In contrast, the pvdhfr S93H mutation, changing amino acids from AGC (Ser) to CAC (His) located away from the binding pocket of pyrimethamine, was predicted not to interrupt pyrimethamine binding. However, these in silico results will need confirmation in further in vitro or in vivo drug sensitivity studies.

An additional marker for SP resistance in P. falciparum is increased copies number of GTP cyclohydrolase I gene (pfgch1). GTP cyclohydrolase is another important enzyme in folate biosynthesis, and an increased copy number might compensate for the fitness loss associated with triple and quadruple mutations in $p f d h f r$ and $p f d h p s$ [41, 42]. So far, there is limited number of reports on gene amplification of $p v g c h 1$, therefore still no finding of the association of mutations in $p v d h f r / p v d h p s$ and $p v g c h 1$ copy number variation. Whether copy number variation (CNV) in the P. vivax orthologous gene $p v g c h 1$ is important in antifolate resistance needs further study. Pvgch1 $\mathrm{CNV}$ was not assessed in the current study, but less likely to be present because of the absence of triple- or quadruple mutations in pvdhfr in our samples.

\section{Conclusions}

This study shows that although wild-type $p v d h f r$ and pvdhps haplotypes have become less frequent in the Afghanistan P. vivax parasite population between 2007 and 2017, but only double and single nonsynonymous mutations in $p v d h f r$ were observed, which would confer only moderate SP resistance. This suggests relatively low drug pressure from SP on the P. vivax parasite population in the study areas. Of the two novel $p v d h f r$ mutations identified in Afghanistan, only the N50I was predicted to moderately affect pyrimethamine binding. 


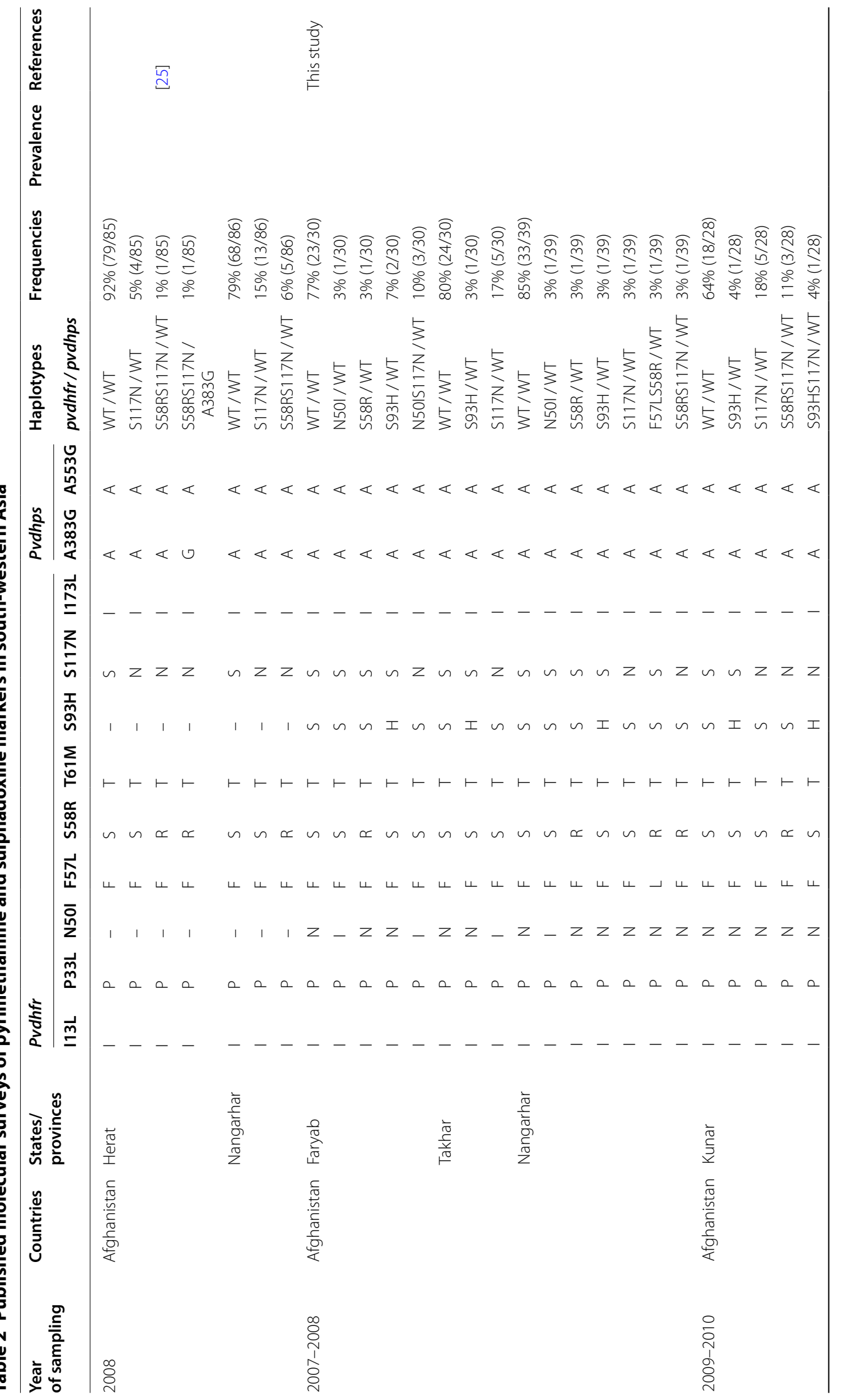




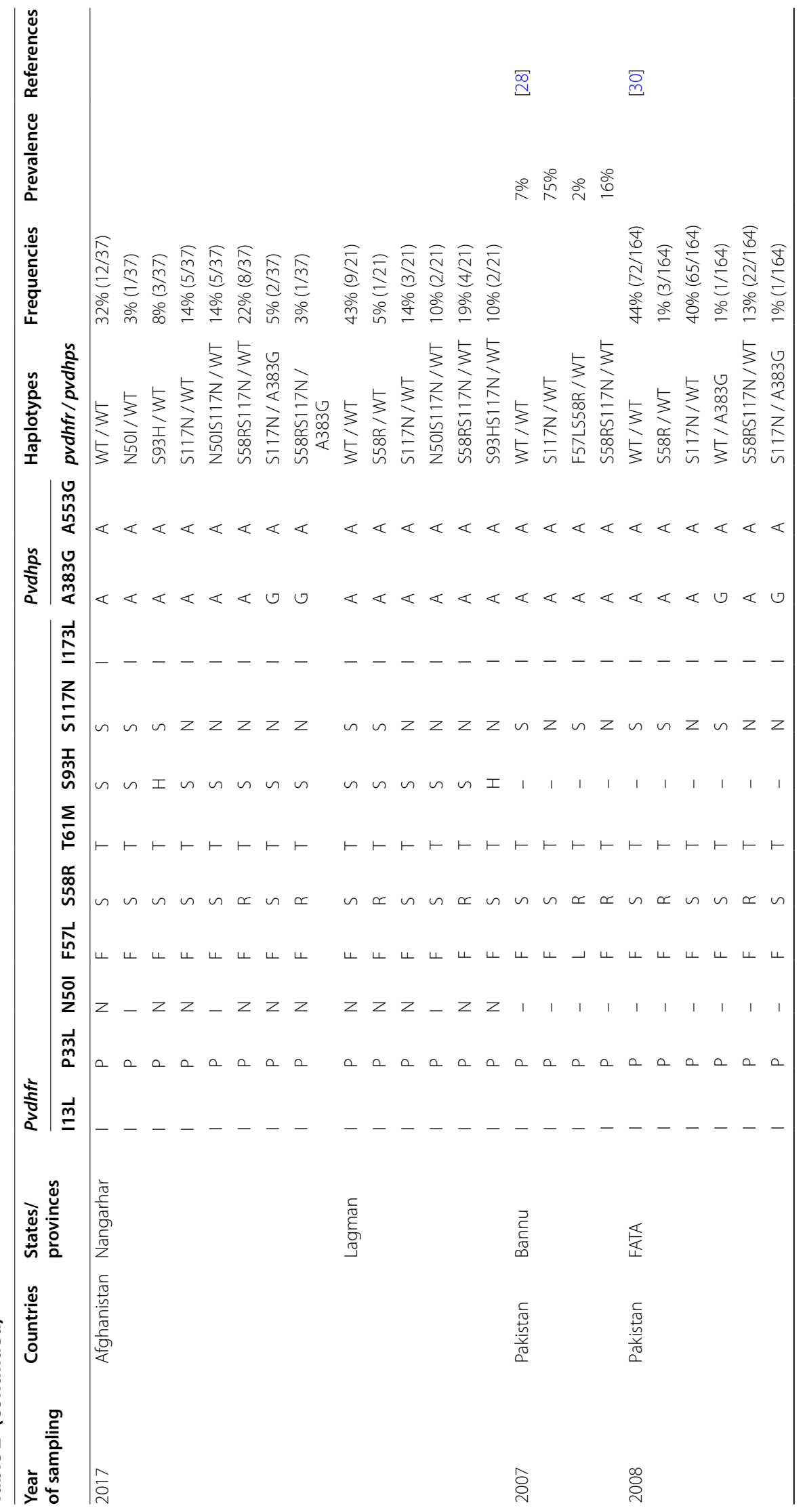




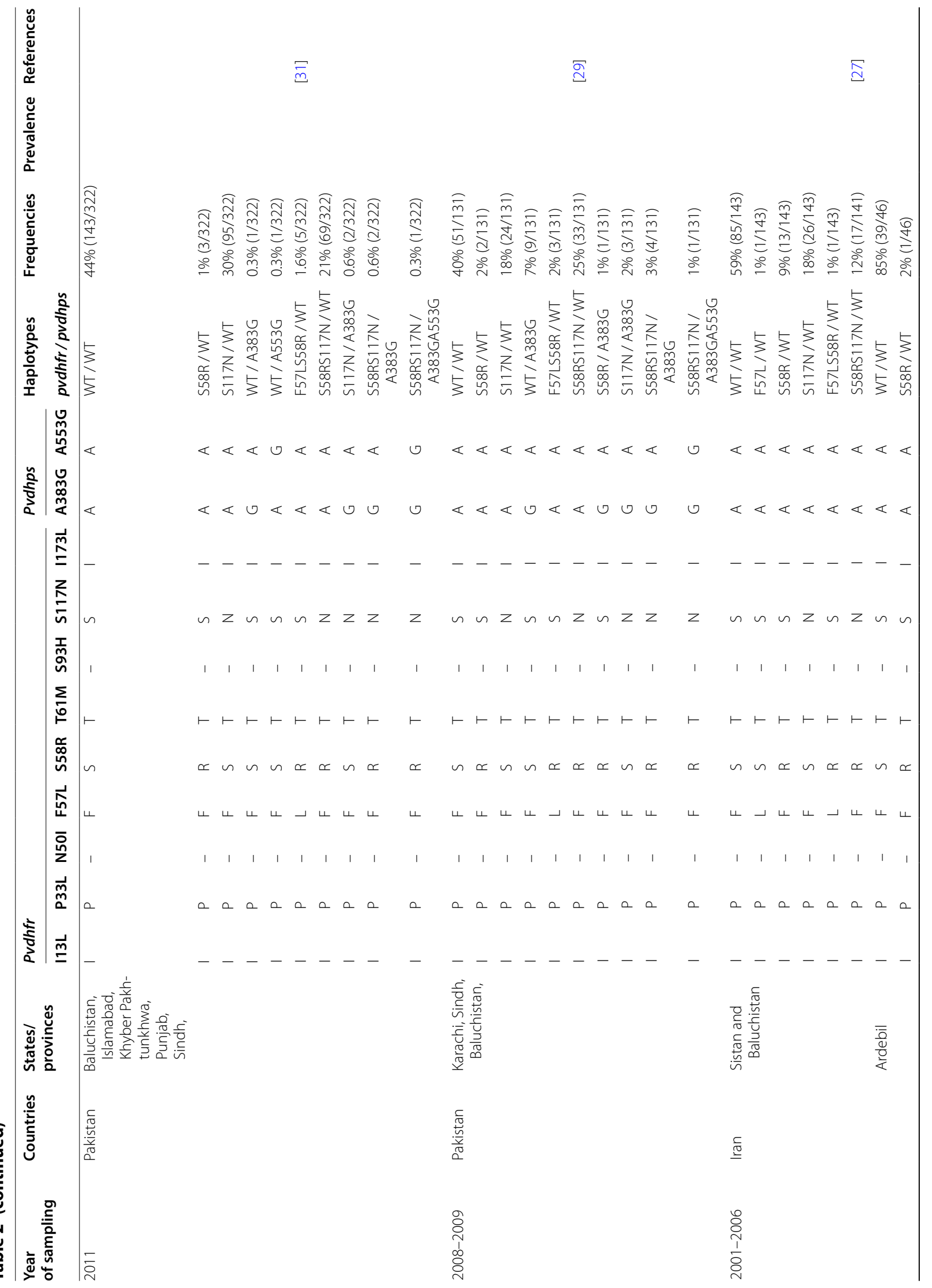




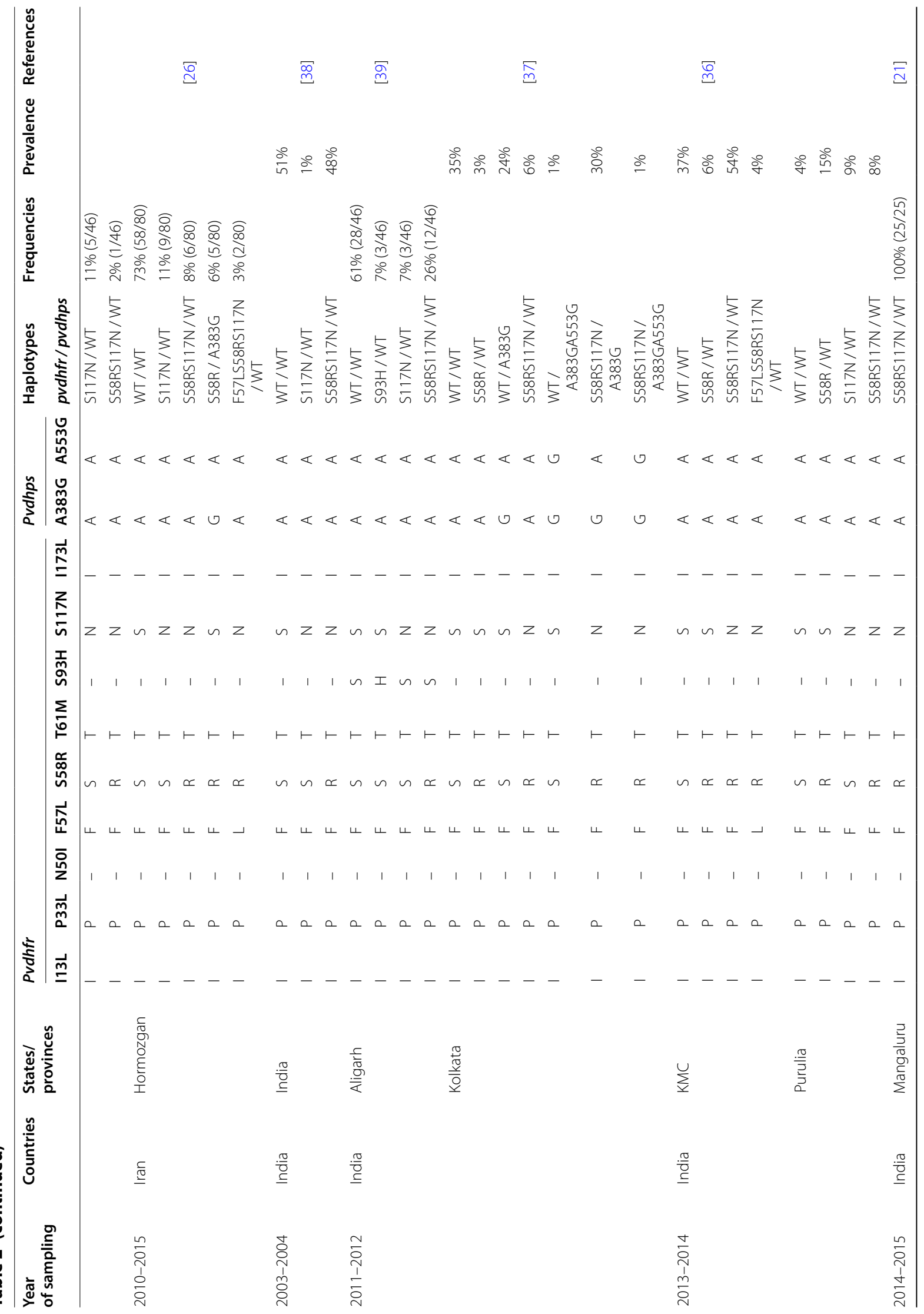




\section{Supplementary information}

Supplementary information accompanies this paper at https://doi. org/10.1186/s12936-020-03319-0.

Additional file 1. Details of PCR and RFLP conditions.

\section{Abbreviations}

pvdhfr: Plasmodium vivax dihydrofolate reductase; pvdhps: P. vivax dihydropteroate synthase; SNPs: Single nucleotide polymorphisms; CQ-PQ: Chloroquine and primaquine; SP: Artesunate and sulfadoxine-pyrimethamine.

\section{Acknowledgements}

This study was supported by Thailand Science Research and Innovation (TSRI), RTA6280006 and Faculty of Tropical Medicine, Mahidol University Thailand and the Wellcome Trust Mahidol University Oxford Tropical Medicine Research Programme.

\section{Authors' contributions}

MI, GRA and AMD designed the study. KR undertook the laboratory experiment. GRA collected the samples. MI, JD, GRA, UB and AMD conducted data analysis.KR, AMD and MI wrote the first draft. All authors read and approved the final manuscript.

\section{Funding}

This study was supported by Thailand Science Research and Innovation (TSRI), RTA6280006 and Faculty of Tropical Medicine, Mahidol University Thailand and the Wellcome Trust Mahidol University Oxford Tropical Medicine Research Programme.

\section{Availability of data and materials}

The dataset generated during the current study are available from corresponding author on reasonable request.

\section{Ethics approval and consent to participate}

Ethical and Scientific procedure of this study were certificated by the ethics committee of the Faculty of Tropical Medicine, Mahidol University, Thailand. The sample materials used in this study were approved by the ethical committee from Department of Disease Control, Ministry of Public Health, and Afghanistan.

\section{Consent for publication}

$$
\text { Not applicable. }
$$

\section{Competing interests}

The authors declare that they have no competing interests.

\section{Author details}

1 Department of Molecular Tropical Medicine and Genetics, Faculty of Tropical Medicine, Mahidol University, 420/6 Rajvithi Road, Bangkok 10400, Thailand. ${ }^{2}$ Nangarhar Medical Faculty, Ministry of Higher Education, Nangarhar University, Jalalabad, Afghanistan. ${ }^{3}$ Centre for Tropical Medicine and Globa Health, Nuffield Department of Medicine, University of Oxford, Oxford, UK. ${ }^{4}$ Mahidol-Oxford Tropical Medicine Research Unit (MORU), Faculty of Tropical Medicine, Mahidol University, Bangkok, Thailand.

Received: 21 April 2020 Accepted: 4 July 2020

Published online: 14 July 2020

\section{References}

1. WHO. World malaria report 2018. Geneva: World Health Organization; 2018.

2. Afghanistan Government. State of Afghan Cities 2015. Afghanistan Government: Kabul; 2015

3. Afghanistan Ministry of Health. National monitoring and evaluation plan 2018-2022. Afghanistan Ministry of Health: Kabul; 2018.
4. Foote SJ, Cowman AF. The mode of action and the mechanism of resistance to antimalarial drugs. Acta Trop. 1994;56:157-71.

5. Peters W. Drug resistance in malaria parasites of animals and man. Adv Parasitol. 1998;41:1-62.

6. Battle KE, Karhunen MS, Bhatt S, Gething PW, Howes RE, Golding N, et al. Geographical variation in Plasmodium vivax relapse. Malar J. 2014;13:144.

7. de Pécoulas PE, Tahar R, Ouatas T, Mazabraud A, Basco LK. Sequence variations in the Plasmodium vivax dihydrofolate reductase-thymidylate synthase gene and their relationship with pyrimethamine resistance. Mol Biochem Parasitol. 1998;92:265-73.

8. Imwong M, Pukrittakayamee S, Looareesuwan S, Pasvol G, Poirreiz J, White NJ, et al. Association of genetic mutations in Plasmodium vivax dhfr with resistance to sulfadoxine-pyrimethamine: geographical and clinical correlates. Antimicrob Agents Chemother. 2001;45:3122-7.

9. Kongsaeree $P$, Khongsuk P, Leartsakulpanich U, Chitnumsub P, Tarnchompoo B, Walkinshaw MD, et al. Crystal structure of dihydrofolate reductase from Plasmodium vivax: pyrimethamine displacement linked with mutation-induced resistance. Proc Natl Acad Sci USA. 2005:102:13046-51.

10. Leartsakulpanich U, Imwong M, Pukrittayakamee S, White NJ, Snounou G, Sirawaraporn W, et al. Molecular characterization of dihydrofolate reductase in relation to antifolate resistance in Plasmodium vivax. Mol Biochem Parasitol. 2002;119:63-73.

11. Thongdee P, Kuesap J, Rungsihirunrat K, Tippawangkosol P, Mungthin M, Na-Bangchang K. Distribution of dihydrofolate reductase (dhfr) and dihydropteroate synthase (dhps) mutant alleles in Plasmodium vivax isolates from Thailand. Acta Trop. 2013;128:137-43.

12. Tantiamornkul K, Pumpaibool T, Piriyapongsa J, Culleton R, Lek-Uthai U. The prevalence of molecular markers of drug resistance in Plasmodium vivax from the border regions of Thailand in 2008 and 2014. Int J Parasitol Drugs Drug Resist. 2018;8:229-37.

13. Rungsihirunrat K, Sibley CH, Mungthin M, Na-Bangchang K. Geographical distribution of amino acid mutations in Plasmodium vivax DHFR and DHPS from malaria endemic areas of Thailand. Am J Trop Med Hyg. 2008;78:462-7.

14. Rungsihirunrat K, Na-Bangchang K, Hawkins VN, Mungthin M, Sibley CH. Sensitivity to antifolates and genetic analysis of Plasmodium vivax isolates from Thailand. Am J Trop Med Hyg. 2007;76:1057-65.

15. de Pécoulas PE, Tahar R, Yi P, Thai KH, Basco LK. Genetic variation of the dihydrofolate reductase gene in Plasmodium vivax in Snoul, northeastern Cambodia. Acta Trop. 2004;92:1-6.

16. Lu F, Lim CS, Nam DH, Kim K, Lin K, Kim TS, et al. Mutations in the antifolate-resistance-associated genes dihydrofolate reductase and dihydropteroate synthase in Plasmodium vivax isolates from malaria-endemic countries. Am J Trop Med Hyg. 2010;83:474-9.

17. Auliff A, Wilson DW, Russell B, Gao Q, Chen N, Ngoc A, et al. Amino acid mutations in Plasmodium vivax DHFR and DHPS from several geographical regions and susceptibility to antifolate drugs. Am J Trop Med Hyg. 2006;75:617-21.

18. Asih PB, Marantina SS, Nababan R, Lobo NF, Rozi IE, Sumarto W, et al. Distribution of Plasmodium vivax pvdhfr and pvdhps alleles and their association with sulfadoxine-pyrimethamine treatment outcomes in Indonesia. Malar J. 2015;14:365.

19. Barnadas C, Timinao L, Javati S, Iga J, Malau E, Koepfli C, et al. Significant geographical differences in prevalence of mutations associated with Plasmodium falciparum and Plasmodium vivax drug resistance in two regions from Papua New Guinea. Malar J. 2015;14:399.

20. Barnadas C, Tichit M, Bouchier C, Ratsimbasoa A, Randrianasolo L, Raherinjafy $R$, et al. Plasmodium vivax dhfr and dhps mutations in isolates from Madagascar and therapeutic response to sulphadoxine-pyrimethamine Malar J. 2008;7:35

21. Joy S, Ghosh SK, Achur RN, Gowda DC, Surolia N. Presence of novel triple mutations in the pvdhfr from Plasmodium vivax in Mangaluru city area in the southwestern coastal region of India. Malar J. 2018;17:167.

22. Kaur S, Prajapati SK, Kalyanaraman K, Mohmmed A, Joshi H, Chauhan VS. Plasmodium vivax dihydrofolate reductase point mutations from the Indian subcontinent. Acta Trop. 2006:97:174-80.

23. Imwong M, Pukrittayakamee S, Rénia L, Letourneur F, Charlieu JP, Leartsakulpanich $U$, et al. Novel point mutations in the dihydrofolate reductase gene of Plasmodium vivax: evidence for sequential selection by drug pressure. Antimicrob Agents Chemother. 2003:47:1514-21. 
24. Prajapati SK, Verma A, AdakT, Yadav RS, Kumar A, Eapen A, et al. Allelic dimorphism of Plasmodium vivax gam-1 in the Indian subcontinent. Malar J. 2006;5:90.

25. Zakeri S, Afsharpad M, Ghasemi F, Raeisi A, Safi N, Butt W, et al. Molecular surveillance of Plasmodium vivax dhfr and dhps mutations in isolates from Afghanistan. Malar J. 2010;9:75.

26. Maghsoodloorad S, Hosseinzadeh N, Haghighi A, Solgi R, Yusuf MA, Hatam G. Amino acid mutation in Plasmodium vivax dihydrofolate reductase (dhfr) and dihydropteroate synthetase (dhps) genes in Hormozgan Province, southern Iran. J Vector Borne Dis. 2019;56:170.

27. Zakeri S, Motmaen SR, Afsharpad M, Djadid ND. Molecular characterization of antifolates resistance-associated genes, (dhfr and dhps) in Plasmodium vivax isolates from the Middle East. Malar J. 2009;8:20.

28. Khatoon L, Baliraine FN, Bonizzoni M, Malik SA, Yan G. Prevalence of antimalarial drug resistance mutations in Plasmodium vivax and Plasmodium falciparum from a malaria-endemic area of Pakistan. Am J Trop Med Hyg. 2009;81:525-8.

29. Raza A, Ghanchi NK, Khan MS, Beg MA. Prevalence of drug resistance associated mutations in Plasmodium vivax against sulphadoxinepyrimethamine in southern Pakistan. Malar J. 2013:12:261.

30. Zakeri S, Afsharpad M, Ghasemi F, Raeisi A, Kakar Q, Atta H, et al. Plasmodium vivax: prevalence of mutations associated with sulfadoxine-pyrimethamine resistance in Plasmodium vivax clinical isolates from Pakistan. Exp Parasitol. 2011;127:167-72.

31. Khattak AA, Venkatesan M, Khatoon L, Ouattara A, Kenefic LJ, Nadeem MF, et al. Prevalence and patterns of antifolate and chloroquine drug resistance markers in Plasmodium vivax across Pakistan. Malar J. 2013;12:310.

32. Snounou G, Viriyakosol G, Jarra W, Thaithong S, Brown KN. Identification of the four human malaria parasite species in field samples by the polymerase chain reaction and detection of a high prevalence of mixed infections. Mol Biochem Parasitol. 1993:58:283-92.

33. Imwong M, Pukrittayakamee $S$, Cheng $Q$, Moore C, Looareesuwan S, Snounou G, et al. Limited polymorphism in the dihydropteroate synthetase gene (dhps) of Plasmodium vivax isolates from Thailand. Antimicrob Agents Chemother. 2005;49:4393-5.

34. Laskowski RA, MacArthur MW, Moss DS, Thornton JM. PROCHECK: a program to check the stereochemical quality of protein structures. J Appl Crystallogr. 1993;26:283-91.
35. Trott O, Olson AJ. AutoDock Vina: improving the speed and accuracy of docking with a new scoring function, efficient optimization, and multithreading. J Comput Chem. 2010;31:455-61.

36. Das S, Banik A, Hati AK, Roy S. Low prevalence of dihydro folate reductase (dhfr) and dihydropteroate synthase (dhps) quadruple and quintuple mutant alleles associated with SP resistance in Plasmodium vivax isolates of West Bengal. India Malar J. 2016;15:395.

37. Ganguly S, Saha P, Chatterjee M, Maji AK. Prevalence of polymorphisms in antifolate drug resistance molecular marker genes pvdhfr and pvdhps in clinical isolates of Plasmodium vivax from Kolkata. India Antimicrob Agents Chemother. 2014;58:196-200.

38. Saralamba N, Nakeesathit S, Mayxay M, Newton PN, Osorio L, Kim JR, et al. Geographic distribution of amino acid mutations in DHFR and DHPS in Plasmodium vivax isolates from Lao PDR. India and Colombia Malar J. 2016;15:484.

39. Zakai HA. Prevalence of mutation and phenotypic expression associated with sulfadoxine-pyrimethamine resistance in Plasmodium falciparum and Plasmodium vivax. Folia Parasitol. 2013;60:372-6.

40. Hastings MD, Sibley CH. Pyrimethamine and WR99210 exert opposing selection on dihydrofolate reductase from Plasmodium vivax. Proc Natl Acad Sci USA. 2002;99:13137-411.

41. Hamour S, Melaku Y, Keus K, Wambugu J, Atkin S, Montgomery J, et al. Malaria in the Nuba Mountains of Sudan: baseline genotypic resistance and efficacy of the artesunate plus sulfadoxine-pyrimethamine and artesunate plus amodiaquine combinations. Trans R Soc Trop Med Hyg. 2005;99:548-54.

42. Kidgell C, Volkman SK, Daily J, Borevitz JO, Plouffe D, Zhou Y, et al. A systematic map of genetic variation in Plasmodium falciparum. PLoS Pathog. 2006;2:e57.

\section{Publisher's Note}

Springer Nature remains neutral with regard to jurisdictional claims in published maps and institutional affiliations.

Ready to submit your research? Choose BMC and benefit from:

- fast, convenient online submission

- thorough peer review by experienced researchers in your field

- rapid publication on acceptance

- support for research data, including large and complex data types

- gold Open Access which fosters wider collaboration and increased citations

- maximum visibility for your research: over $100 \mathrm{M}$ website views per year

At BMC, research is always in progress.

Learn more biomedcentral.com/submissions 